\title{
A Study of Anxiety Disorders in Terms of Severity and Prevalence in Patients of Major Depressive Disorder in a Tertiary Care Centre
}

\author{
Richa Rani $^{1}$, Neeru Bala ${ }^{2}$, Parshotam Dass Garg ${ }^{3}$, Aashish Bansal ${ }^{4}$ \\ ${ }^{1}$ Third year Postgraduate Student, Department of Psychiatry, GMC Amritsar \\ ${ }^{2}$ Associate Professor, Department of Psychiatry, GMC Amritsar \\ ${ }^{3}$ Professor and Head, Department of Psychiatry, GMC Amritsar \\ ${ }^{4}$ First year Postgraduate Student, Department of Pathology, Adesh Institute of Medical Sciences \& Research, Bathinda
}

\section{Address for correspondence:}

\section{Dr Neeru Bala.}

216 Bhullar Avenue, FGC Road, Amritsar-143001

E-mail:jpneeru15@gmail.com,drneeru15@yahoo.in.

\begin{abstract}
:
Background: Depression is a disorder of major public health importance. Over the last 50 years, large number of studies have been published from India addressing various aspects of depression. The objective of the current study was to study the socio-demographic characteristics and anxiety as co-morbidity in patients with major depressive disorder. Method: This was a cross sectional study conducted in tertiary care hospital in which 100 patients diagnosed with major depressive disorder, according to ICD-10 were assessed for presence of anxiety disorder as psychiatric Comorbidity using MINI and severity of anxiety was assessed using HAM-A. Results: Current study showed major depressive disorder is more common among females 59\%, married 79\%, housewife 50\%, $61 \%$ had first episode of depression and $27 \%$ had family history of major depressive disorder. There was $48 \%$ presence of any anxiety disorder among total major depressive disorder patients. Among which $25 \%$ had generalized anxiety disorder, $9 \%$ obsessive compulsive disorder, 5\% panic disorder, 4\% agoraphobia, $4 \%$ post traumatic stress disorder and $1 \%$ social anxiety disorder among total patients with major depressive disorder. The maximum number of patients $43 \%$ had mild to moderate level of anxiety, $32 \%$ had mild anxiety, $19 \%$ had moderate to severe anxiety and $6 \%$ had severe anxiety. Conclusion: There is a high prevalence of anxiety disorders in major depressive disorder which is oftenly ignored because of symptom overlap between anxiety and major depression. This study is important because of increasing prevalence of psychiatric comorbidity among the patients of major depressive disorders lead to impaired functioning in patients with MDD. Therefore, monitoring of symptoms as well as functioning during the long-term management MDD could be crucial to achieve the functioning remission.
\end{abstract}

Keyword: Major depressive disorder, MDD, Co-morbidity, Anxiety.

\section{Introduction}

Major Depressive Disorder (MDD) is a global issue. According to the World Health Organization (2004), unipolar depression is currently in third place worldwide on the burden of disease list and is projected to be the second leading cause of worldwide disability in developed countries by 2020. A large-scale national survey on the comorbidity of depression was carried out in the U.S., principally by the University of Michigan. The results indicated that more than half of all patients with a DSM-III-R diagnosis of major depressive disorder were associated with a co morbid anxiety disorder.

Comorbidity can occur for various reasons. It can be a chance occurrence or can be due to the conjunction of independent risk factors; or it may develop because two disorders have shared risk factors, or because one disorder predisposes the individual for the other, or the comorbid condition may be a multiform expression of one of the pure disorders or a third independent disorder. ${ }^{[1]}$

In psychiatry, when distinct symptoms like anxiety and depression co-occur, whether they indicate the presence of two distinct clinical entities or whether they are two components of a single disorder is mostly a matter of speculation, as we know little about the etiology and patho-physiologic interrelationship of mental illnesses. Psychiatric comorbidity is a prevalent phenomenon and remains a challenge for the effective delivery of mental health services. Recent community surveys show that among those with a psychiatric disorder the lifetime prevalence of more than one diagnosis is about $50 \% .^{[2]}$ 
A recent study attempted to address this issue from a prospective, longitudinal approach. They reported that $72 \%$ of individuals with generalized anxiety disorder (GAD) were diagnosed with comorbid depression and $48 \%$ of individuals with depression also $\operatorname{had} \mathrm{GAD} .^{[3]}$

A recent report base on the large STAR*D population has shown a $46 \%$ prevalence of anxious depression among 1450 Major Depressive Disorder outpatients. ${ }^{[4]}$

\section{Aims and Objectives}

1. To study the socio demographic profile of patients with major depressive disorder.

2. To study the presence of anxiety disorders in patients with major depressive disorder.

3. To evaluate the severity of anxiety disorders in patients with major depressive disorder.

The present study was conducted in the department of Psychiatry, Government Medical College, Amritsar. Patients with major depressive disorder coming into psychiatry department of Guru Nanak Dev Hospital, Amritsar were taken in the study. The diagnosis was confirmed by a senior consultant in the department of psychiatry, GMC Amritsar. A total sample of 100 patients who met the inclusion criteria and gave informed consent were included in the study.

Sample Size: A size of total 100 diagnosed cases was taken for the study.

Study Design: Present study was a cross sectional descriptive, tertiary care-hospital based study.

Duration of the Study: The data collection lasted from 1st January 2017 to 31st December 2017.

Statistical Analysis: The data were analyzed using SPSS software version 21 .

\section{Tools and Procedure:}

1. An informed consent form for the study, including the methodology and need to study.

2. Proforma for identification, socio demographic details, present history, past history and family history of the patient.

3. Mini international neuropsychiatric interview (M.I.N.I.).

4. HAM-A (Hamilton Anxiety rating Scale).

\section{Results:}

The present study was carried out in the Department of Psychiatry, Government Medical College and Hospital Amritsar. It was conducted to study the prevalence of co-morbid psychiatric disorders, and the socio-demographic profile of the patients with major depressive disorder.

\section{Table 01}

\begin{tabular}{|l|c|c|}
\hline Socio-demographic Profile & No. of Patients & Percentage \\
\hline Sex & & \\
\hline Female & 59 & $59 \%$ \\
\hline Male & 41 & $41 \%$ \\
\hline Religion & & \\
\hline Sikh & 72 & $72 \%$ \\
\hline
\end{tabular}

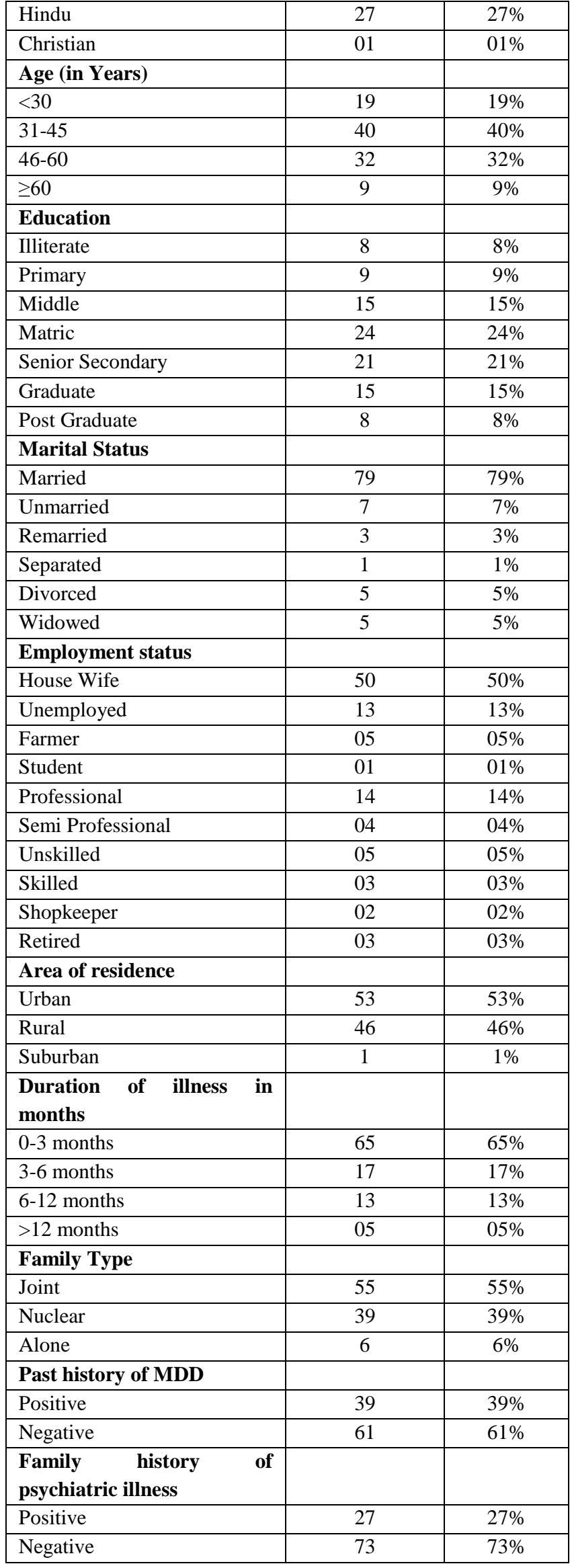

In our study, most of the patients were females 59 (59\%) and males were $41(41 \%)$. Which is similar to another study which shows women have 1.5 times greater prevalence than men for Major Depressive Disorder by Kongsuk T, et al (2010) ${ }^{[16]}$ and according to Munoli RN, et al (2014) ${ }^{[11]} 54 \%$ were females. 


\section{International Journal of Innovative Research in Medical Science (IJIRMS) \\ Volume 03 Issue 11 Nov 2018, ISSN: 2455-8737, Imp. Factor - 4.102 \\ Available online at $-\underline{w w w . i j i r m s . i n}$}

In our study mean age \pm S.D. was $40.57 \pm 11.66$ in patients with MDD. Buturak SV, et al (2011) ${ }^{[7]}$ mean age of the sample under study was $49.9 \pm 12.8$. Gili $\mathrm{M}$ et al $(2013)^{[9]}$ the mean age was 47.76 .

Most of the patient was studied upto matric (24\%) followed by higher secondary (21\%); the findings of previous studies were $28 \%$ had 9-12 years of education. Cancino A, et al (2018), ${ }^{[10]}$ did the study of factors associated with Psychiatric comorbidity in depressed patients in Primary Healthcare in Chile, where most of the $(41.6 \%)$ patients were high school educated.

In the present study, $50 \%$ were housewives, $8 \%$ were illiterate and most of the patient were studied upto matric (24\%) followed by higher secondary $(21 \%)$.similar to Munoli RN, et al (2014) ${ }^{[11]}$ in which $40 \%$ were homemakers.
In the present study, maximum number of patients with Major Depressive Disorder were married 79 (79\%) similar results were seen in studies by Munoli RN, et al (2014) ${ }^{[11]}$ showed $76 \%$ were married, Zimmerman M, et al (2000), ${ }^{[5]}$ showed $44.5 \%$ were married. Papan Thaipisuttikal PI, et al (2014) ${ }^{[6]} 53 \%$ were married. Gili M et al (2013) ${ }^{[9]}$ showed $58.3 \%$ were married.

In the present study most of the patients were from urban area 53 $(53 \%)$ which is also evidenced by Gili M, et al (2013), ${ }^{[9]}$ where $73.4 \%$ were from urban area and Reddy MV and Chandrashekhar CR (1998) ${ }^{[12]}$ in which prevalence of depression was more in urban than rural.

In the present study; 39 (39\%) had a past history of depressive illness and $61 \%$ had a first episode of depression, similar to a previous study of Munoli RN, et al (2014) $)^{[11]}$ in which $60(60 \%)$ had a first episode of depression.

Table 02

\begin{tabular}{|l|l|c|c|}
\hline Score (HAM-A) & Variable & No. of Patients (n=100) & Percentage (\%) \\
\hline$<17$ & Mild Anxiety & 32 & $32 \%$ \\
\hline $18-24$ & Mild to Moderate Anxiety & 43 & $43 \%$ \\
\hline $25-30$ & Moderate to Severe Anxiety & 19 & $19 \%$ \\
\hline$>30$ & Severe Anxiety & 06 & $06 \%$ \\
\hline Total & & 100 & $100 \%$ \\
\hline
\end{tabular}

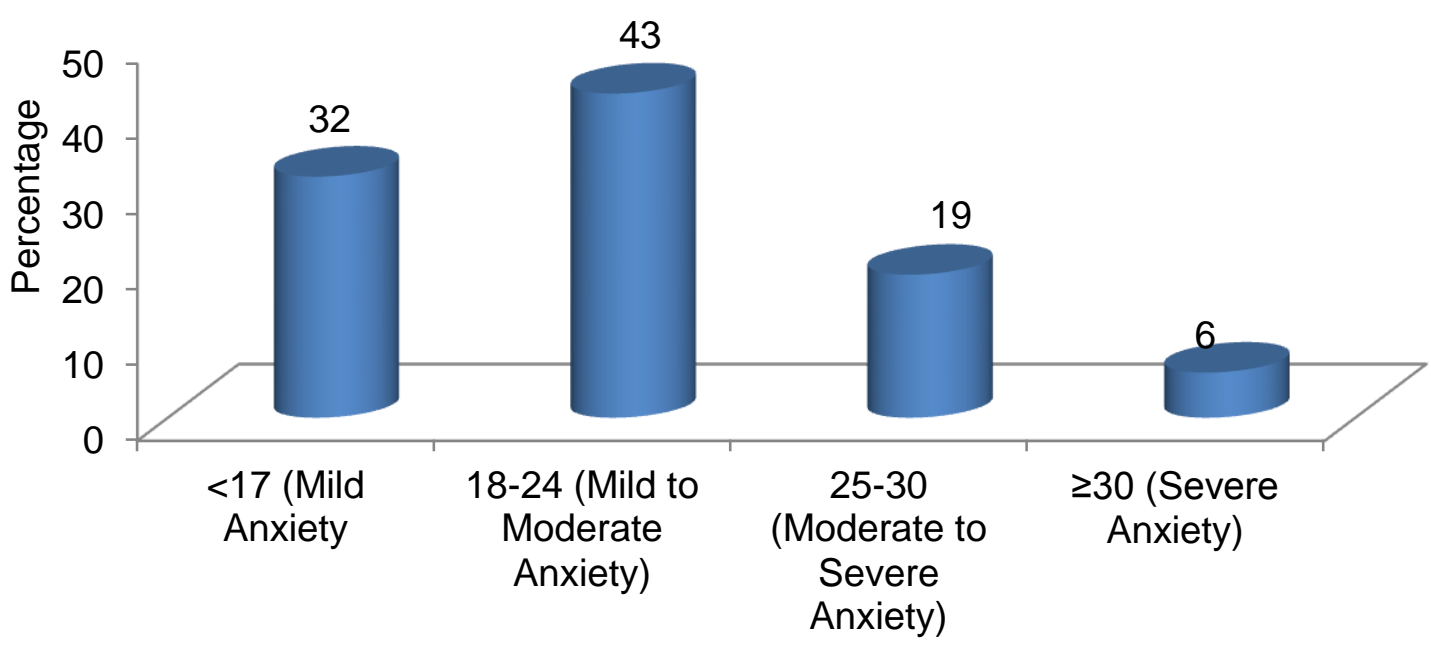

Severity of anxiety

Table 03

\begin{tabular}{|l|c|c|}
\hline Type of anxiety disorder comorbidity in major depressive disorder & No. of Patients (n) & Percentage (\%) \\
\hline Panic Disorder & 05 & $05 \%$ \\
\hline Agoraphobia & 04 & $04 \%$ \\
\hline Social Phobia (Social Anxiety Disorder) & 01 & $01 \%$ \\
\hline Obsessive Compulsive Disorder & 09 & $09 \%$ \\
\hline Post traumatic stress disorder & 04 & $04 \%$ \\
\hline Generalized Anxiety Disorder & 25 & $25 \%$ \\
\hline TOTAL & 48 & $48 \%$ \\
\hline
\end{tabular}




\section{International Journal of Innovative Research in Medical Science (IJIRMS) \\ Volume 03 Issue 11 Nov 2018, ISSN: 2455-8737, Imp. Factor - 4.102 \\ Available online at $-\underline{w w w . i j i r m s . i n}$}

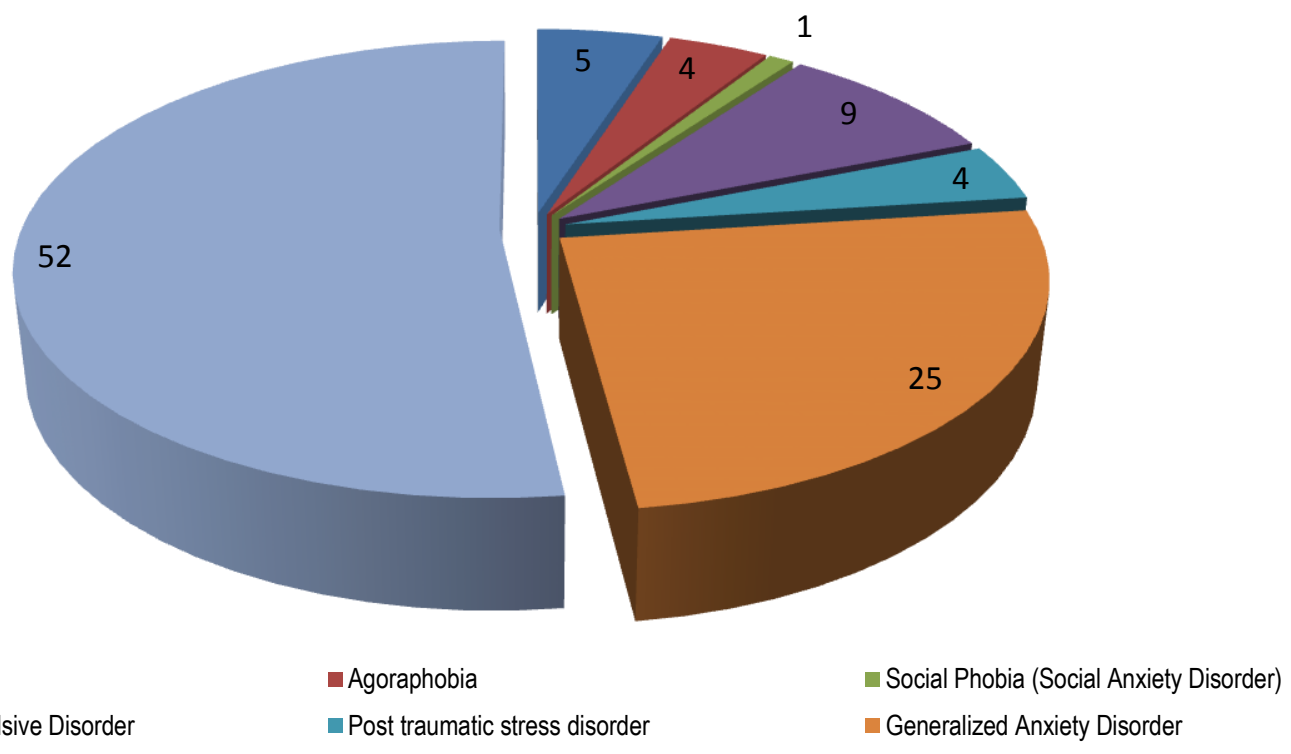

- Panic Disorder

- Obsessive Compulsive Disorder

- Without Anxiety Disorder
- Generalized Anxiety Disorder

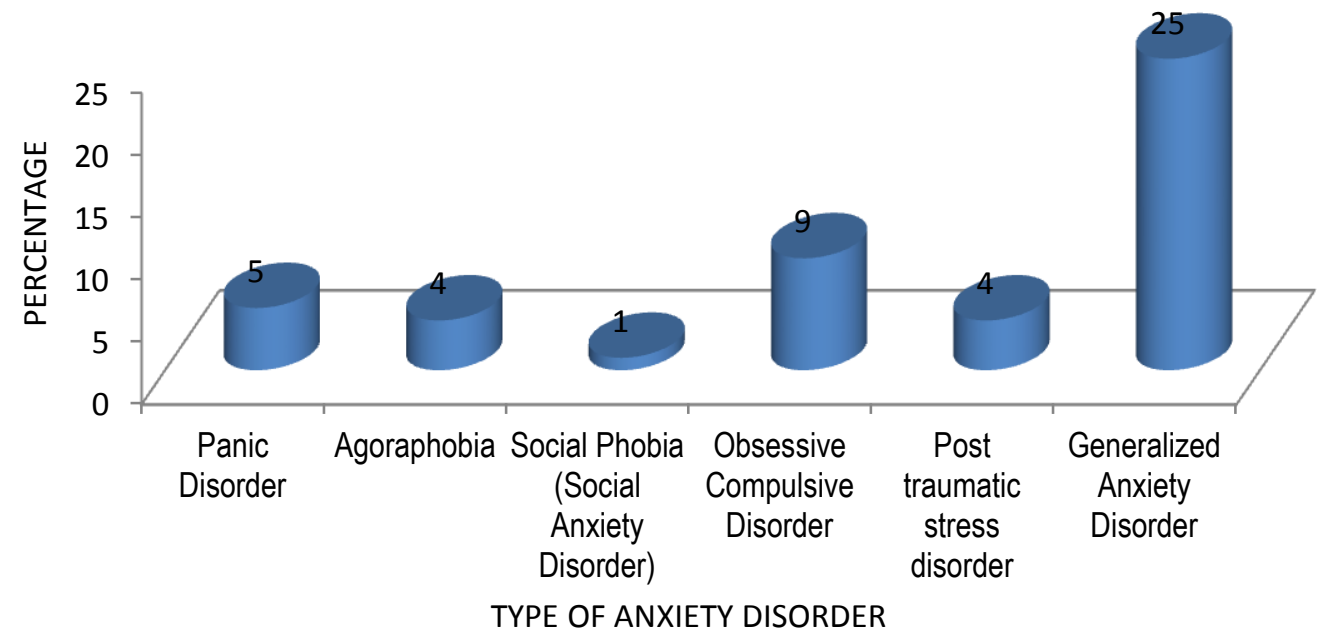

In the present study, it was found that nearly half $(43 \%)$ of the patients had mild to moderate anxiety, less than half $(32 \%)$ were having mild anxiety, $19 \%$ had moderate to severe anxiety and only $6 \%$ had severe anxiety. This was nearly similar to findings of case control study of Sinha M, Sanyal D (2012). ${ }^{[14]}$

Sahoo S and Khess CR (2010) ${ }^{[15]}$ found that a majority of the patients had moderate anxiety and very few patients were having severe anxiety.

In the present study most common comorbidity is the presence of anxiety disorder 48 (48\%) of the total patients with MDD. Which included $5(5 \%)$ panic disorder $4(4 \%)$ Agoraphobia $1(1 \%)$ social anxiety disorder, 9 (9\%) obsessive compulsive disorder, 4 (4\%) post traumatic stress disorder and $25(25 \%)$ Generalized anxiety disorder. In a similar study by Munoli RN, et al (2014) $)^{[11]}$ showed that the most common psychiatric comorbidity in depressive patients was $46 \%$ anxiety disorder. Also similar results of $46 \%$ were seen in STAR*D study Howland RH, et al (2009). ${ }^{[13]}$

Small DM, (2008) ${ }^{[17]}$ showed $27.4 \%$ prevalence of anxiety disorders in total 439 patients with MDD. In another study by King-Kallimanis B, et al (2009) ${ }^{[13]}$ has shown that 12 month prevalence of comorbid anxiety disorder in patients with MDD was $60.6 \%$ in $18-64$ years age group.

\section{Conclusions}

As Major Depressive Disorder is very common in Primary Health Care Services patient with psychiatric co-morbidity like anxiety overlapping with depressive disorder tend to be less responsive to treatment so there is a higher extent of loss in mental abilities and the disease become chronic. So there is a great need for further research in the field of co-morbidity. 


\section{Limitation}

The sample under study was of small size cross sectional study. Moreover, our study had relied upon the hospital population and not the community sample and some of the population like divorced, widow, retired persons were under represented in the study.

\section{References}

[1] Klein DN. Different reasons for comorbidity require different solutions. World Psychiatry. 2004;3:28.

[2] Merikangas KR, Kalaydjian A. Magnitude and impact of comorbidity of mental disorders from epidemiologic surveys. Curr Opin Psychiatry. 2007;20(4):353-8.

[3] Moffitt TE, Harrington H, Caspi A, Goldberg D, Gregory $\mathrm{AM}$, Poulton R, et al. Depression and generalized anxiety disorder: cumulative and sequential co-morbidity in a birth cohort followed prospectively to age 132years. Arch Gen Psychiatry 2007;64:651-60.

[4] Fava M, Alpert JE, Carmin CN, Wisniewski SR, Trivedi MH, Biggs MM, et.al: Clinical correlates and symptom patterns of anxious depression among patients with major depressive disorder in STAR*D. Psychol MED 2004; 34 (7): 1299-1308.

[5] Zimmerman M, McDermut W, Mattia JI. Frequency of anxiety disorders in psychiatric outpatients with major depressive disorder. American Journal of Psychiatry. 2000 Aug 1;157 (8):1337-40.

[6] Papan Thaipisuttikul PI, Waleeprakhon P, Wisajun P, Jullagate S. Psychiatric comorbidities in patients with major depressive disorder. Neuropsychiatric disease and treatment. 2014;10: 2097-2103.

[7] Buturak SV, Basterzi AD, Yazici A, Yazici K, Acar ST. Comorbid disorders in outpatients with major depressive disorder and their sociodemographical aspects. Journal of Mood Disorders. 2011 Jan 1;1 (1):7-13.

[8] King-Kallimanis B, Gum AM, Kohn R. Comorbidity of depressive and anxiety disorders for older Americans in the national comorbidity survey-replication. The American Journal of Geriatric Psychiatry. 2009 Sep 1;17 (9):782-92.
[9] Gili M, Toro MG, Armengol S, García-Campayo J, Castro A, Roca M. Functional impairment in patients with major depressive disorder and comorbid anxiety disorder. The Canadian Journal of Psychiatry. 2013 Dec;58 (12):679-8

[10] Hirschfeld RM. The comorbidity of major depression and anxiety disorders: recognition and management in primary care. Primary care companion to the Journal of clinical psychiatry. 2001;3 (6):244-54.

[11] Munoli RN, Sharma PS, Kongasseri S, Bhandary RP, Praharaj SK. Clinical features and comorbidities of depression among inpatients in a tertiary care centre. Andhra Pradesh Journal of Psychological Medicine. 2014;15 (2):193-200.

[12] Reddy VM, Chandrashekhar CR. Prevalence of mental and behavioral disorders in India: A metaanalysis. Indian J Psychiatry 1998; 40:149-57.

[13] Howland RH, Rush AJ, Wisniewski SR. Trivedi MH, Warden D, Fava $\mathrm{M}$, et al. Concurrent anxiety and substance use disorders among outpatients with major depression: Clinical features and effect on treatment outcome. Drug Alcohol Depend 2009; 99:248-60.

[14] Sinha M, Sanyal D. Impact of stressful life events in depressed women: A case-control study. International Medical Journal, 2012;19 (3): 211-214.

[15] Sahoo S, Khess CR. Prevalence of depression, anxiety, and stress among young male adults in India: a dimensional and categorical diagnoses-based study. J Nerv Ment Dis. 2010 Dec;198 (12):901-4.

[16] Kongsuk T, Kittirattanapaiboon P, Kenbubpha K, Sukawaha S, Leejongpermpoon J. The prevalence of major depressive disorders in Thailand: results from the Epidemiology of Mental Disorders National Survey 2008. In World Psychiatric Association Section on Epidemiology and Public Health meeting, Prediction in psychiatric epidemiology-from childhood and adolescence to adulthood $2010 \mathrm{Jul}$ (pp. 11-14).

[17] Small DM, Simons AD, Yovanoff P, Silva SG, Lewis CC, Murakami JL, March J. Depressed adolescents and comorbid psychiatric disorders: are there differences in the presentation of depression?. Journal of Abnormal Child Psychology. 2008 Oct 1;36 (7):1015-28. 